\title{
CERAMIC PANEL FOR SOUND INSULATION APPLICATION
}

\author{
Wan Aiman Hakim Wan Maliki, Muhd. Hafeez Zainulabidin \\ Faculty of Mechanical Engineering \& Manufacturing \\ Universiti Tun Hussein Onn Malaysia (UTHM)
}

\begin{abstract}
In order to reduce noise nowadays, many researcher find different way to solve this problem. One of the ways to reduce noise is by using a sound insulation. This research has been conducted in order to produce high density sound insulation panel made from ceramic. The fabrication of ceramic panel undergo several processes which are milling, mixing, forming, drying and sintering process. The ceramic panel of different types of forming were developed as square plate $110 \mathrm{~mm} \times 110 \mathrm{~mm}$ with a constant thickness of $5 \mathrm{~mm}$. Type of forming were used for this particular study are slip casting and uniaxial press. The composition used were $100 \%$ clay and $90 \%$ $+10 \%$ clay cement. The transmission loss were determined by using acoustic insulation test. The apparatus consists of sound level meter, portable speaker and computer. The Sound Pressure Levels (SPL) were taken at $250 \mathrm{~Hz}, 500 \mathrm{~Hz}, 1000 \mathrm{~Hz}, 2000 \mathrm{~Hz}$ and $4000 \mathrm{~Hz}$ which based on 1 octave frequency bands. The analysis shown that the sample $90 \%+10 \%$ clay cement casting has the higher transmission loss in the lower frequency region, the sample $90 \%+10 \%$ clay cement uniaxial press has the higher transmission loss in the middle frequency region and lastly the sample $100 \%$ clay uniaxial press has the higher transmission loss in higher frequency region. The sample also were tested using Charpy impact test in order to gain their impact energy and impact strength. The tests were according to ASTM-D256. Charpy impact test can determines the amount of energy absorbed by a material during fracture. The analysis shown that the impact energy of the ceramic panel have a small percentage different. It can be concluded that uniaxial press is better than the slip casting in forming ceramic insulation panel.
\end{abstract}

Keywords: Sound insulation, Acoustic ceramic panel, Charpy impact test, Ceramic forming, Scanning Electron Microscopy (SEM)

\section{Introduction}

Noise is unwanted sound produced by many sources. For example, men playing guitar, a running engine, a vibrating of air conditioning, an operating machine, and so on. The difference between sound and noise depends upon the listener and the circumstances. Rock music can be pleasurable sound to one person and an annoying noise to another. In either case, it can be hazardous to a person's hearing if the sound is loud and if he or she exposed long and often enough. Noise is one of the most common occupational health hazards. In heavy industrial and manufacturing environments, permanent hearing loss is the main health concern.

Sound is produced by vibrating objects and reaches the listener's ears as waves in the air or other media. When an object vibrates, it causes slight changes in air pressure. These air pressure changes travel as waves through the air and produce sound (Peters, Smith, \& Hollins, 2011). To prevent bad outcomes of noise exposure, noise levels should be reduced to acceptable levels.
The best way to reduce noise is to use engineering modifications to the noise source itself, or to the environment area. One of best way to reduce noise is use panel of sound insulation. Sound can transmitted through wall by making the structure vibrates. The vibration generates new sound waves but the intensity will reduced on the other side. This is call Transmission loss. Transmission loss can be measure in Sound Reduction Index in decibel (dB). Sound Reduction Index or Transmission loss, is measure of the effectiveness of the wall, floor or barrier to be restricting of the sound to travel. Transmission loss have varies frequency and more loss in higher frequency. The higher transmission loss of the wall, the better of the panel for isolation (Peters et al., 2011).

There are two types of sound insulation, airborne and impact. Airborne sound insulation is used when sound produced directly into the air is insulated and it is determined by using the sound reduction index. Impact sound insulation is used for floating floors and it is 
determined by the sound pressure level in the adjacent room (Peters et al., 2011).

In order to reduce the problem, there many incentives have been taken by the government such as making a guideline and law in order to shows the acceptable range of noise for a different type of situation. In addition, many of researcher now days were taking a close look on the level of noise and its effect against human. In addition, a rules and regulation such as OSHA and NIOSH have set the daily permissible exposure to noise.

In this particular research, it will be focusing on ceramic material with difference type of forming. Ceramic is very good in sound insulation. Therefore, in order to produce more economical and easy to work material, this research will conduct to identify the best forming. The combination of ceramic and other material have been used in several research but in making these difference type of forming never be explore.

Ceramics are classified as inorganic and non-metallic materials. Ceramics are all around us. This category of materials includes things like tile, bricks, plates, glass, and toilets. Depending on their method of formation, ceramics can be dense or lightweight. Typically, they will demonstrate excellent strength and hardness properties; however, they are often brittle in nature. Taking mixtures of clay, earthen elements, powders, and water and shaping them into desired forms generally make ceramics. Once the ceramic has been shaped, it is fired in a high temperature.

\section{Literature Review}

Many theories have been proposed to explain about panel for sound insulation application. The importance to investigate because the panel for sound insulation are exposed to a variation of pressure and temperature throughout its whole cycle life depend of usability. This is due to applications of panel in almost all industries, hospitality and many more. Many types and design of panel have been introduced nowadays in order to match with its users.

Although the previous research covers a wide variety of panel with difference types of materials. However, nothing for panel with difference types of ceramic forming. Apart from that, difference types of material used as reference for this research. In this research, it is review on the analysis of sound isolation panel with fire resistance and high durability of difference types of ceramic forming.

In this chapter, discussed about acoustic and noise control. Acoustic is production, control, transmission, reception and effects of sound. At certain time, sound can be noise; noise can be control with absorption material, sound transmission loss and many more.
After that, the type of material that can be use also discussed in this chapter. Ceramic material is very high density with low porosity. That feature make ceramic is suitable to make transmission loss material. Ceramic can be produced with variety of forming, for example slip casting, uniaxial pressing, Sol-Gel and many more.

\subsection{Sound insulation and sound transmission loss.}

Sound insulation is the reduction of sound energy from transmission of sound through materials (Peters et al., 2011). Sound is transmitted through most walls and floors by setting the entire structure into vibration. This vibration generates new sound waves of reduced intensity on the other side. As sound travels reaches a surface, there is reflection, absorption and transmission. Sound insulation is the ability of a material to minimize the transmission of acoustic energy through the material (Ruiz, 2012). Good sound insulation are obtained with materials which are reasonable to heavy mass, and are impervious. For example in figure 2.6 show how the sound insulation work. The energy from sound source have reduce from $100 \%$ to $10 \%$ when the energy transmitted through the sound insulation.

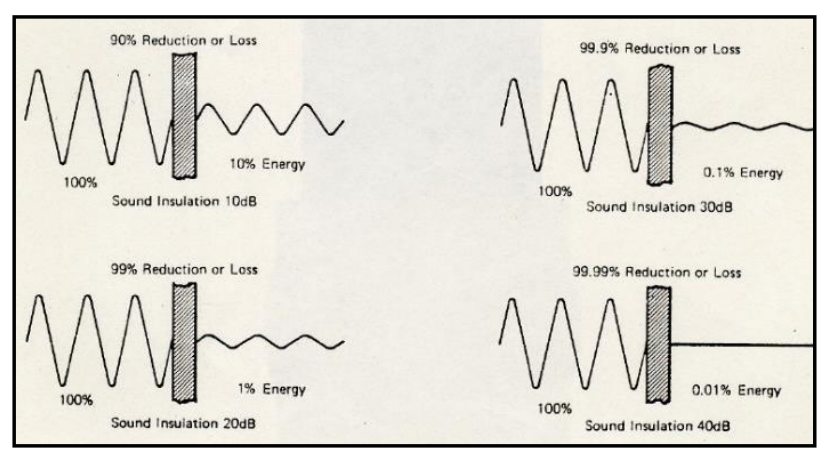

Figure 1: How the sound insulation work (Peters et al., 2011).

Transmission loss (TL) in general describes the accumulated decrease in intensity of a waveform energy as a wave propagates outwards from a source, or as it propagates through a certain area or through a certain type of structure (Egan, 2000). On the other hand, the decrease in power that occurs during transmission from one point to another. Measurement of transmission loss can be in terms of decibels $(\mathrm{dB})$.

The amount of sound energy transmitted through a partition will depend on the area of the partition, S. For a given amount of sound energy transmitted through the partition, the level of reverberant sound created in the receiving room will depend upon the amount of absorption in the receiving room, A (Wareing, 2014). The level difference between the two rooms is given by: 
$\mathrm{SPL} 1-\mathrm{SPL} 2=\mathrm{R}-10 \log \mathrm{S}+10 \log \mathrm{A}$

Where:

SPL1 = Average level in the source room $(\mathrm{dB})$

SPL2 = Average level in the receiving room $(\mathrm{dB})$

$\mathrm{R}=$ Sound reduction index

$\mathrm{S}=$ Area of partition $\left(\mathrm{m}^{\wedge} 2\right)$

A = Absorption in receiving room $\left(\mathrm{m}^{\wedge} 2\right)$

This equation, which is used in the laboratory measurement of R, may be used for predicting noise levels in real situations where the sound distribution in each room is reverberant acceding the ISO 3741 (Acoustic Determination of sound power level of noise sources using sound pressure level - Precision methods for reverberation room.). It does not include effects of flanking transmission (Rienstra \& Hirschberg, 2015).

\subsection{Types of ceramic forming.}

The raw materials used in making ceramics include inorganic solid powders with precisely controlled purity, particle size and distribution (Kingery, 1977). These raw materials are formulated for specific properties and functionality, then mixed with a binding agent or binder. After that, they are shaped and cut to precise requirements and fired at extreme heat. Ceramic was firing to removes the moisture and binders. To make ceramic with high strength, ceramic is firing again, powder particles are sintered together and the products shrink due to reduced porosity (Chris Woodford, 2016). Figure 2 show the product shrink due to reduced porosity. This process results in products of extreme density and hardness

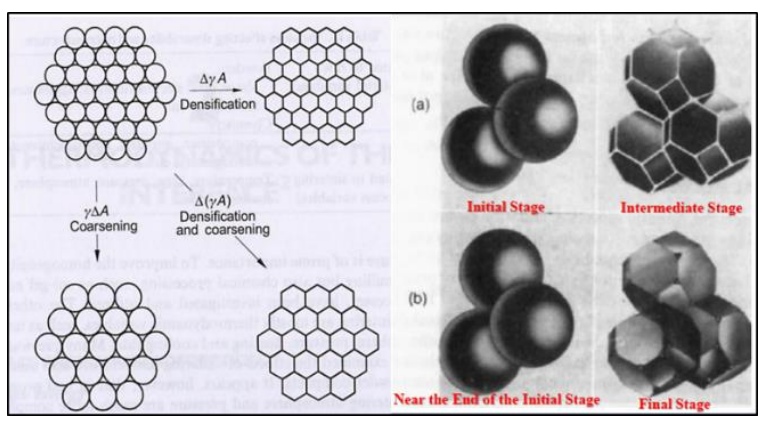

Figure 2: Both densification and coarsening result in reduction in free energy of the system. Therefore, there are competitive processes (Paul, 2009).

\subsubsection{Slip casting}

Slip casting consists of making a slurry of the green body constituents, then casting this in a porous mould, typically of plaster because of the porosity. It can be considered as a low pressure filtration method where capillary suction provides the driving force or liquid removal and formation of a cast body as shown in figure 3 .

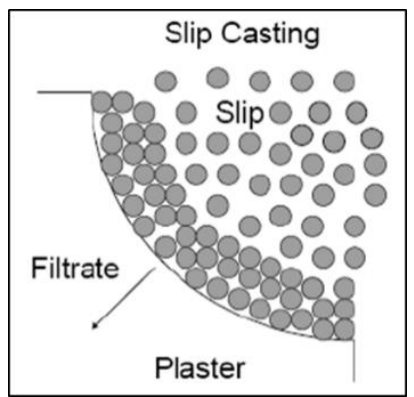

Figure 3: The process of slip into plaster (Siegel, 1993).

As much of the slurry liquid at or near the mold surface is absorbed in the pores in the mold, a layer of solid is formed by the interlocking solid particles in the region near the mold surface. As the process continues, the thickness of solid layer increases and the mold pores continue to absorb slurry liquid. Slip casting is a slow process since the casting rate decreases parabolically with the thickness of the cast layer (Siegel, 1993). The setting time can differ from a few minutes to form a thin wall to several hours for producing a thick part.

The following factors are to be considered while preparing a proper slip for casting, the volume fraction of the ceramic in the slurry, particle size, particle shape, particle surface charges, and the degree of dispersion. The particle size distribution is another important factor as it influences the packing in the green body and hence the green density. The particle surface condition is critical in slip casting as it affects the state of dispersion of the slurry. A good dispersion with high solid content is preferred in slip casting as it can lead to high green density and low pore volume.

The main disadvantage of slip casting is the long time required to cast components in the mold and subsequent drying of them, which results in requiring a huge amount of inventory of molds, high labor force, and a large working space. However, the ability to achieve a better particle packing and pore size distribution compensates some of these drawbacks.

\subsubsection{Slip casting}

In this method, the powder confined in a die is compacted by a pressure applied along a single axial direction, as displayed in Figure 4. However, uniaxial pressing results in density variations, which can cause cracking and distortion during the sintering process. 


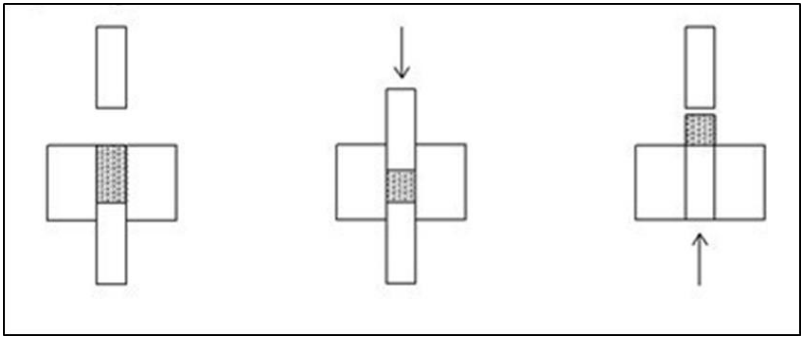

Figure 4: Schematic illustrating uniaxial pressing.

\section{Methodology}

This chapter describes the equipment that have been used to conduct the experiments, which related to acoustic insulation ceramic panel. The apparatus involve such as sound level meter (TES 1258 Sound Analyzer) to measure Sound Pressure Level in unit $\mathrm{dB}$, Testometric Material Machine to measure compression testing, Scanning Electron Microscopy to know material structure and to measure the fire resistance. This sound insulation panel are applicable to isolate the noise and heat with high resilience.

Three tests have been done in this study which is the sound insulation test, Charpy impact test, and to morphological the surface of the materials. All tests are important to know the characteristic and limitation of the material if can withstand with the noise and impact. The experiment has been done by following the available standard that related to the test.

\subsection{Planning}

In this particular research, series of plan and steps have been made in order to conduct all the experiment and testing. In order to make sure this research runs smoothly, the project follow the process show in figure 5

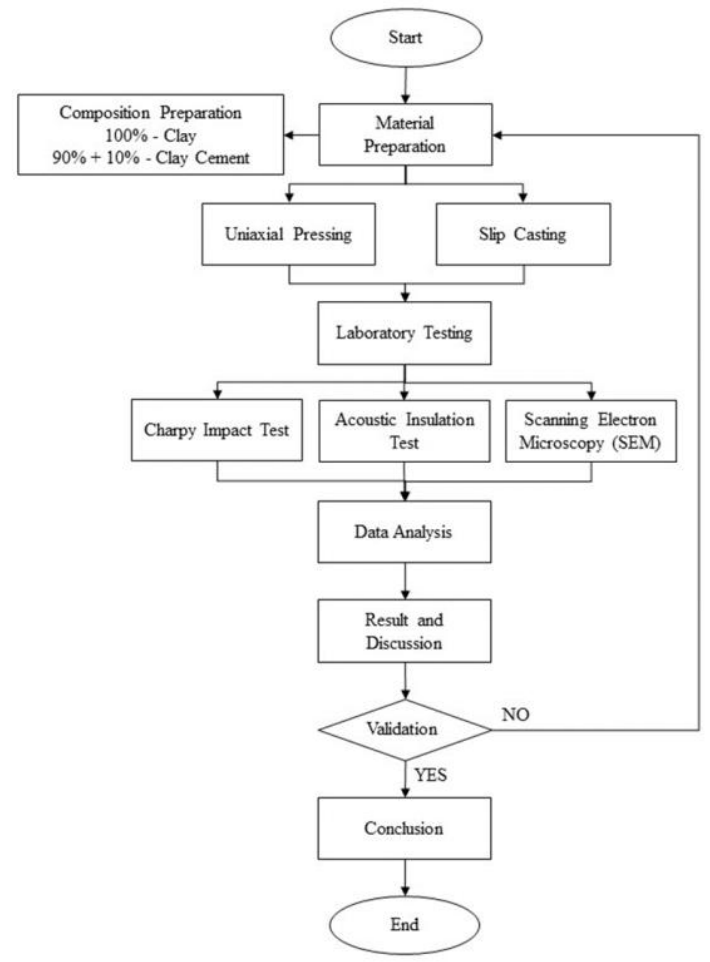

Figure 5: Flow chart for the research

\subsection{Material preparation}

There were specific procedure in order to produce the sample, therefore these are the procedures that have been used in making the sample. The entire sample will going through a milling, sieving, mixing, forming, drying and sintering processes. The difference between each sample is the types forming process. In figure 5 show the flow chart for material preparation. 


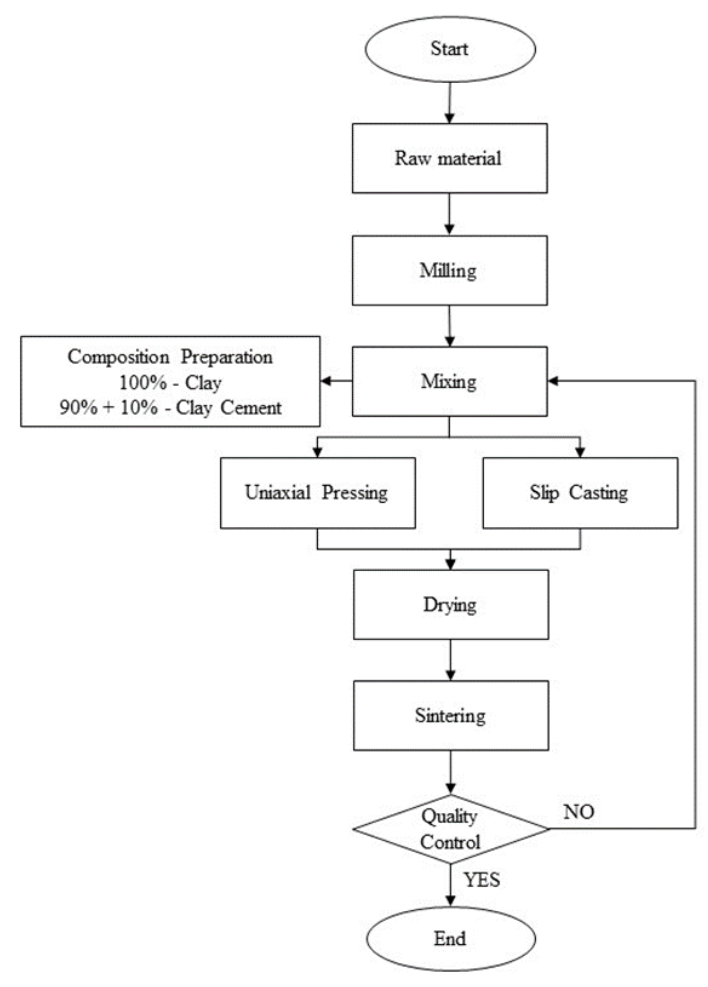

Figure 5: Flow chart for material preparation

\subsection{Acoustic insulation test}

The insulation test is to determine the acoustic properties of the material. In this research, the material are $100 \%$ clay and $90 \%+10 \%$ clay cement. The apparatus consists of sound level meter, portable speaker and computer. In figure 6 , show setup for insulation test. The reading were took in $250 \mathrm{~Hz}, 500 \mathrm{~Hz}, 1000 \mathrm{~Hz}, 2000 \mathrm{~Hz}$ and $4000 \mathrm{~Hz} 1$ octave frequency bands. All the data were collected five time and were calculated to get the average.

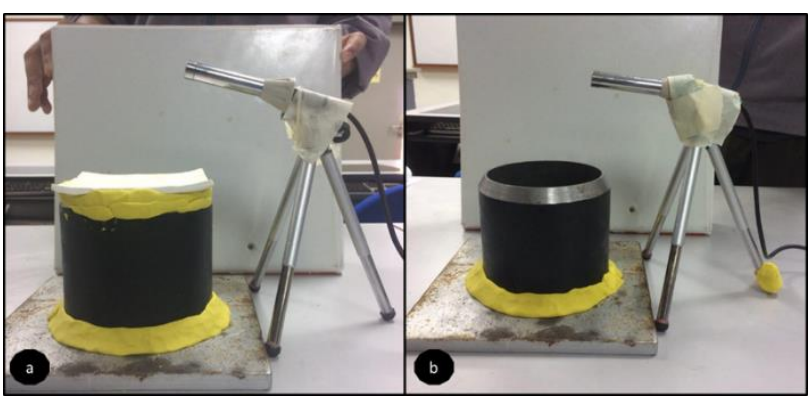

Figure 6: Setup of insulation test (a) before adding ceramic panel and (b) after adding ceramic panel

The specimen were formed in square plate with $110 \mathrm{~mm}$ x $110 \mathrm{~mm}$ and $5 \mathrm{~mm}$ thickness. The sample of ceramic were attached to top hollow cylinder according to figure 6 . This specimen used to measure sound insulation each type of ceramic forming. From the data that has been collected, the transmission loss could be calculate using formula as followed:

Transmission Loss $(\mathrm{dBA})=$ SPL $1-$ SPL 2

Where:

$$
\begin{aligned}
& \text { SPL } 1(\mathrm{dBA})=\text { Before adding panel } \\
& \text { SPL } 2(\mathrm{dBA})=\text { After adding panel }
\end{aligned}
$$

\subsection{Charpy impact test}

Charpy impact test were done in order to seek information on the energy absorbed by a standard notched specimen while breaking under an impact load of the difference type of forming. The test were done in UTHM polymer laboratory. The experiment was done 5 times in order to find the average value of the material to minimize error. The following equation were been used in this test:

Area cross section sample $=$ Width sample $(\mathrm{m}) \mathrm{x}$ (Thickness (m) - Notch Deep (m))

Impact strength $=\frac{\text { Average impact energy }(\mathrm{J})}{\text { Area cross section sample }\left(\mathrm{m}^{2}\right)}$

\subsection{Acoustic insulation test}

Microstructure analysis is conducting by using Scanning Electron Microscope to examine the microstructure of ceramic surface. The samples were subjected to the standard metallographic procedure before it can be further analyzed under SEM.

\section{Results and Discussion}

\subsection{Acoustic insulation test}

Figure 7 show the transmission loss of ceramic panel with difference forming versus frequency. For sample 100 $\%$ clay casting, the transmission loss is higher at $500 \mathrm{~Hz}$ frequency with $47.30 \mathrm{dBA}$ and the lower at $125 \mathrm{~Hz}$ frequency with $27.75 \mathrm{dBA}$. The transmission loss drop at $2000 \mathrm{~Hz}$ with $35.80 \mathrm{dBA}$. For sample $90 \%+10 \%$ clay cement casting, the transmission loss is much fluctuated compare with other sample. The higher of transmission loss is at $500 \mathrm{~Hz}$ frequency with $49 \mathrm{dBA}$ and lower at 1000 $\mathrm{Hz}$ frequency with $21.79 \mathrm{dBA}$.

For sample $100 \%$ clay uniaxial press, the transmission loss is higher at $500 \mathrm{~Hz}$ frequency with 46.33 $\mathrm{dBA}$ and the lower at $250 \mathrm{~Hz}$ frequency with $19.05 \mathrm{dBA}$. For the last sample $90 \%+10 \%$ clay cement uniaxial 
press, the transmission loss is higher $500 \mathrm{~Hz}$ frequency with $55.85 \mathrm{dBA}$ and the lower at $250 \mathrm{~Hz}$ frequency with 18 dBA. The conclusion, the sample $90 \%+10 \%$ clay cement casting good in the lower frequency, the sample 90 $\%+10 \%$ clay cement uniaxial press is good in the middle frequency and lastly the sample $100 \%$ clay uniaxial press good in higher frequency.

The transmission loss is dependent on the density within thickness and material on the density of the partition ad the frequency of the noise. The increased parameter it provides greater transmission loss. But, less thick sample provides lower transmission loss meaning the poor sound insolating performance (Egan, 1988). However, according (Hansen, 2004), the most excellent isolating material are those which compact, thick and heavy. Increasing the mass of partition forces sound waves to work harder and use more vitality to pass through the medium. The amount of transmission loss is highly influenced by density, mass and thickness of material.

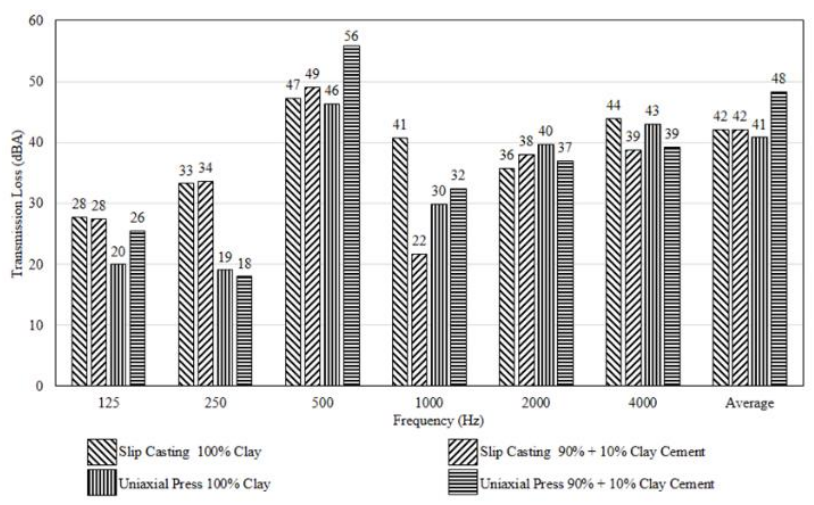

Figure 7: Transmission Loss for all sample.

Table 1: Transmission Loss for all sample.

\begin{tabular}{|c|c|c|c|c|}
\hline \multirow{3}{*}{$\begin{array}{c}\text { Frequency } \\
(\mathrm{Hz})\end{array}$} & \multicolumn{3}{|c|}{ Transmission Loss (dBA) } \\
\cline { 2 - 5 } & \multicolumn{2}{|c|}{ Slip Casting } & \multicolumn{2}{c|}{ Uniaxial Press } \\
\cline { 2 - 5 } & $100 \%$ & $90 \%$ Clay & $100 \%$ & $90 \%$ Clay \\
& Clay & $10 \%$ Cement & Clay & $10 \%$ Cement \\
\hline 125 & 27.75 & 27.50 & 19.97 & 25.50 \\
\hline
\end{tabular}

\begin{tabular}{|c|c|c|c|c|}
\hline 250 & 33.25 & 33.70 & 19.05 & 18.00 \\
\hline 500 & 47.30 & 49.00 & 46.33 & 55.85 \\
\hline 1000 & 40.70 & 21.70 & 29.85 & 32.40 \\
\hline 2000 & 35.80 & 38.07 & 39.63 & 36.95 \\
\hline 4000 & 43.95 & 38.73 & 43.03 & 39.25 \\
\hline Average & 42.08 & 42.06 & 40.83 & 48.24 \\
\hline
\end{tabular}

\subsection{Charpy impact test}

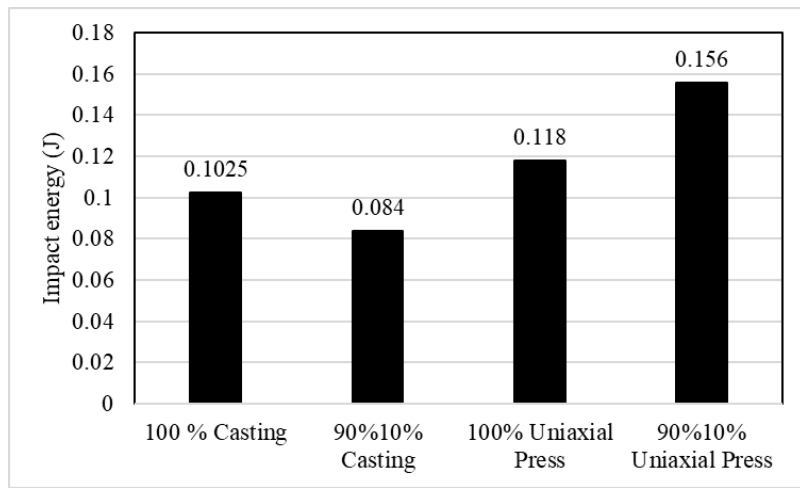

Figure 8: Impact energy versus type of forming graph

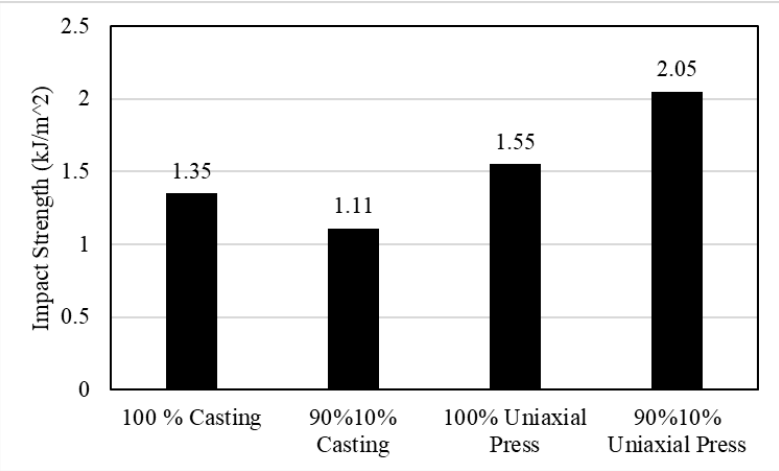

Figure 9: Impact strength versus type of forming graph.

Figure 8 and figure 9 show the graph of an impact energy versus type of forming and impact strength versus types of forming. The graph illustrate that the different type of forming with different impact strength value. From the graph, the value obtained if the uniaxial press forming were used the impact strength of the material is increasing.

As show in graph, $100 \%$ clay casting is higher impact strength value then the $90 \%+10 \%$ clay cement casting in casting forming with is $1.35 \mathrm{~kJ} / \mathrm{m}^{\wedge} 2$ for $100 \%$ clay casting and $1.11 \mathrm{~kJ} / \mathrm{m}^{\wedge} 2 \quad 90 \%$ clay $10 \%$ cement casting. But different on uniaxial press, the $90 \%+10 \%$ clay 
cement uniaxial press higher than the $100 \%$ clay uniaxial press in uniaxial press forming with is $2.05 \mathrm{~kJ} / \mathrm{m}^{\wedge} 2$ and $1.55 \mathrm{~kJ} / \mathrm{m}^{\wedge} 2$ respectively. It can be conclude the uniaxial press forming have higher impact strength compare to casting forming.

\subsection{Scanning Electron Microscopy (SEM)}

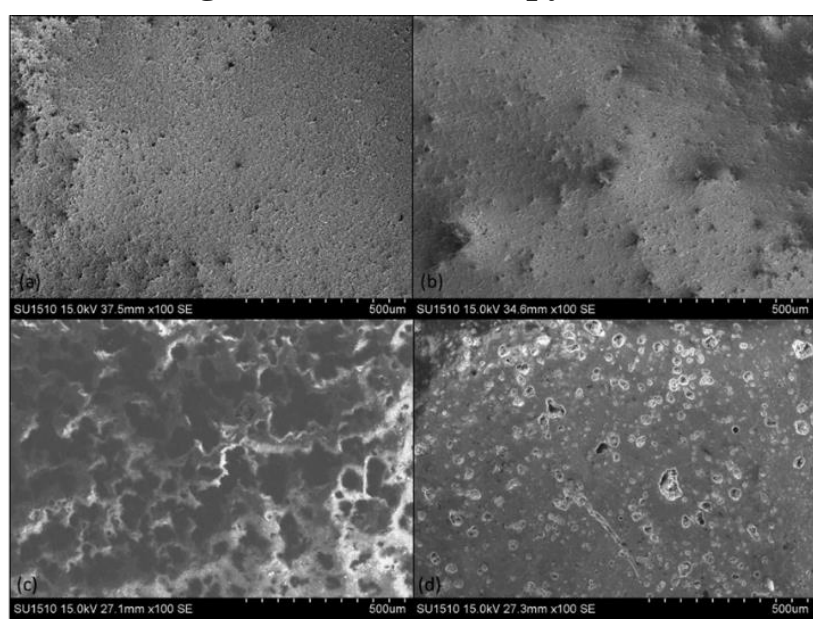

Figure 10: Scanning Electron Microscopy (SEM) of the ceramic panel for (a) $100 \%$ clay casting, (b) $90 \%$ $+10 \%$ clay cement casting, (c) $100 \%$ clay uniaxial press and (d) $90 \%+10 \%$ clay cement uniaxial press.

Comparison is made with according different type of forming which is the determination of transmission loss. According to the data collected in insulation test, sample $90 \%+10 \%$ clay cement casting good at lower frequency. From figure 10 (b) shows that the surface of the sample from casting forming having less pores, which lead to high density surface. According to high density surface, most of the sound wave can't penetration the ceramic panel. Besides, the condition of the surface not really flat causing the sound wave deflect back. This deduced how the transmission loss occur in this sample.

By referring to insulation test result, the most efficient in middle frequency is $90 \%+10 \%$ clay cement uniaxial press. According to figure 10 (d) shows size of the pores is small and distributed throughout the sample. The small pores indicates the sample is high in density and this is due to composition of $90 \%+10 \%$ clay cement uniaxial. The presence of cement fill out the pores left by the clay. A part from that, cement also act as a binder for clay. Therefore, the sound wave that transmitted to the sample surface is deflected back due to high density. Moreover, the energy of the sound ware were reduce due to small pores. This deduced how the transmission loss occur in this sample which are due to high density and small pores.
According the insulation test result, the, most efficient in high frequency is $100 \%$ clay uniaxial press forming. From figure 10 (c), the image shows the sample is abundance in pores that make the sample is low density. Low density sample causing from the forming that be used, that is uniaxial press without water. Sound wave that transmitted onto the sample surface is likely to be absorbed by the pores. In conclusion, not every sample gave the best result in deferent frequencies, which make $90 \%+10 \%$ clay cement casting good at lower frequency, $90 \%+10 \%$ clay cement uniaxial press good at middle frequency and $100 \%$ clay uniaxial press is good at higher frequency.

\section{Conclusion}

This study is all about to understand and gained the transmission loss by using difference type of ceramic forming. Firstly, the ceramic were added to each other according to the composition percentage. After undergo several fabrication process, the panel is square plate with a $110 \mathrm{~mm} \times 100 \mathrm{~mm}$ and thickness is $5 \mathrm{~mm}$. Therefore, the objective to develop the ceramic panel were done successfully. There are four samples for ceramic panel that divided into composition percentage which is $100 \%$ clay and $90 \%$ clay $10 \%$ cement.

The ceramic panel then undergo two type of testing and observation material structure. Firstly the ceramic panel were tested with charpy impact test in order to seek information in the energy absorbed by standard notched specimen while breaking under an impact load. The experiment was done 5 times in order to find the average value of the material to minimize error. After the ceramic panel tested, it shows that $100 \%$ clay casting is higher impact strength value then the $90 \%$ clay $10 \%$ cement casting in casting forming with is $1.35 \mathrm{~kJ} / \mathrm{m}^{\wedge} 2$ for $100 \%$ clay casting and $1.11 \mathrm{~kJ} / \mathrm{m}^{\wedge} 2 \quad 90 \%$ clay $10 \%$ cement casting. But different on uniaxial press, the $90 \%$ clay 10 $\%$ cement uniaxial press higher than the $100 \%$ clay uniaxial press in uniaxial press forming with is $2.05 \mathrm{~kJ} / \mathrm{m}^{\wedge} 2$ and $1.55 \mathrm{~kJ} / \mathrm{m}^{\wedge} 2$ repectively.

Second testing conducted to gained data for the transmission loss. The data collected at 1 octave frequency band in low frequency at $100 \mathrm{~Hz}$ until $250 \mathrm{~Hz}$ while for middle frequency at $500 \mathrm{~Hz}$ until $1000 \mathrm{~Hz}$ and high frequency at $2000 \mathrm{~Hz}$ until $4000 \mathrm{~Hz}$. The analysis that made are investigated the effect of transmission loss on ceramic panel in between two type of ceramic forming. After the ceramic panel tested, it shows that different ceramic forming will get different values of the transmission loss in frequency. The sample $90 \%$ clay 10 $\%$ cement casting good in the lower frequency, the sample $90 \%$ clay $10 \%$ cement uniaxial press is good in the middle frequency and lastly the sample $100 \%$ clay good in higher frequency. 
Observation material structure of ceramic panel using Scanning Electron Microscopy (SEM) showed not every sample give the bbest result in deferent frequencies, which make $90 \%$ clay $10 \%$ cement casting good at lower frequency, $90 \%$ clay $10 \%$ cement uniaxial press good at middle frequency and $100 \%$ clay uniaxial press is good at higher frequency.

The project answered all the objective stated before the project started. It shows that ceramic forming affects the transmission loss.

\section{References}

[1] Binner, J., Hogg, P., \& Murphy, J. (1994). \{Chapter 1 - $\{$ Ceramics $\}$. Advanced Materials Source Book, 1-134. Retrieved December 1, 2017, from https://doi.org/http://dx.doi.org/10.1016/B978-14831-3581-6.50004-3Dunphy, M.P., Patterson, P.M., and Simmie, J.M. High temperature oxidation of ethanol. Part 2- Kinetic modeling. Journal of Chemical Society. Faraday Transactions, Volume 87, (1991), pp. 2549-2560.

[2] Birita, G. S. (2007). Sound Insulation of a Box 129(3), 823-831.
[3] Chris Woodford. (2016). Ceramics - their properties, manufacture, and everyday uses. Retrieved December 9, 2017, from http://www.explainthatstuff.com/ceramics.html

[4] Egan, M. D. (2000). Architectural-AcousticsWorkbook. Retrieved December 11, 2017, from http://www.newmanfund.org/wpcontent/uploads/2000_Architectural-AcousticsWorkbook_Egan.pdf.

[5] Ismail, L. (2012). Acoustic and durability performances of Arenga Pinnata panel. Vasa, (February). Retrieved November 9, 2017, from http://medcontent.metapress.com/index/A65RM03P4 874243N.pdf\%5Cnhttp://eprints.uthm.edu.my/2653/

[6] Khyati. (2000). Ceramics: An introduction \&amp; history. Retrieved December 11, 2017, from http://www.khyaticeramics.com/about_ceramics.php.

[7] Kingery, W. D. (1977). Introduction to Ceramics. Journal of The Electrochemical Society, 124(3), 152C. https://doi.org/10.1149/1.2133296.

[8] Kugler, K., Wiegrebe, L., Grothe, B., Kossl, M., Gurkov, R., Krause, E., \& Drexl, M. (2014). Lowfrequency sound affects active micromechanics in the human inner ear. Royal Society Open Science, 1(2), 140166-140166. https://doi.org/10.1098/rsos.140166. 